\title{
КОРОНО-КОМПОЗИТЫ В РУССКОМ ЯЗЫКЕ
}

\author{
ВВЕДЕНИЕ
}

Объектом исследования являются окказиональные наименования композитного типа с первым элементом короно-, которые в последнее время в большом количестве появились в журналистских текстах, также в интернете - в сфере «mass self-communication» (согласно определению в работе: Castells 9): в сообщениях на интернет-форумах, в социальных сетях, в комментариях и др. Это языковое явление непосредственно связано с пандемией COVID-19 (аббревиатура от англ. COronaVIrus Disease 2019) - тяжёлой респираторной инфекции, вызываемой коронавирусом SARS-CoV-2 (как одним из семи «человеческих» коронавирусов). Английский термин coronavirus был введен группой вирусологов в статье, опубликованной в ноябре 1968 г. в журнале News and Views. Авторы статьи, в частности, писали, что вид данного вируса в микроскопе (частицы более или менее округлены и окружены выступами лепестковой формы) напоминает солнечную корону. Именно этот визуальный образ и лег в основу языковой номинации.

В русском языке данное слово представлено в трех формах записи: корона-вирус, коронавирус и короновирус. В «Русском орфографическом словаре», подготовленном в Институте русского языка им. В. В. Виноградова РАН, предпочитается вторая версия написания, хотя в издании 2012 г. это слово писалось через дефис ${ }^{1}$. С моей точки зрения, наиболее

Prof. dr hab. Aleksander Kiklewicz - Uniwersytet Warmińsko-Mazurski w Olsztynie (University of Warmia and Mazury in Olsztyn), Instytut Dziennikarstwa i Komunikacji Społecznej, Wydział Humanistyczny, Katedra Komunikacji Społecznej; adres do korespondencji: ul. Kurta Obitza 1, 10-725 Olsztyn; e-mail: aleksander.kiklewicz@uwm.edu.pl; ORCID: https://orcid.org/ 0000-0002-6140-6368

\footnotetext{
${ }^{1}$ См. информацию на сайте: gramota.ru.
} 
обоснованным является третье написание: короновирус, т.е. с соединительной гласной «о». Данное сложное существительное образовано от двух корней: корона и вирус, а в таких случаях общепринятым является употребление интерфикса «о», как, например, в слове ракетоноситель (ракета+носитель). В данной статье я, однако, буду употреблять форму на «а» - в соответствии с написанием в орфографическом словаре.

Интерес к данной теме был вызван не только тем, что композитные неологизмы с элементом короно- в относительно небольшом отрезке времени получили значительное распространение, но также и их разнообразием, в частности, с точки зрения семантической структуры. Именно этот, семантический аспект композитных окказионализмов будет предметом исследования.

Языковой материал (76 лексических единиц) был заимствован из интернета - поисковых систем Рамблер.ру, Яндекс.py, Google, Bing, Microsoft Edge. Большой объем этого материала не позволяет указать источники анализируемых единиц (т.е. URL - индивидуальный адрес ресурса в интернете). Это, однако, не должно вызывать у читателей сомнений по поводу достоверности языкового материала.

\section{1. СЛОВООБРАЗОВАНИЕ КАК ЯЗЫКОВОЙ РЕСУРС БЫСТРОГО РЕАГИРОВАНИЯ}

Одним из важнейших элементов языковой картины мира является прагматическая суппозиция номинативных знаков: объекты номинации (т.е. то, что названо) представляют собой важные, значимые с точки зрения языкового сообщества феномены - предметы человеческой деятельности, мысли и информационного обмена. В связи с этим в социальной и когнитивной психологии употребляется понятие салиентности. Данная идея, в частности, выражена в философской поэме «О природе вещей» Тита Лукреция Кара: «Что же до звуков, какие язык производит, - природа // Вызвала их, а нужда подсказала названья предметов».

Салиентность особенно заметна в случае новых наименований, которые отражают явления, непосредственно наблюдаемые в окружающей (физической, биологической, экономической, социальной и др.) среде. Их важнейшая черта - значимость: предметами новых наименований становятся значимые события, значимые отношения и значимые участники событий. 
В номинативных целях наиболее активно используются словообразовательные средства языка: аффиксальное и композитное словообразование. Особенность этого языкового ресурса состоит в том, что с одной стороны - в языковой узус, а при определенных условиях в языковую систему, вводятся новые лексические элементы. Другими словами, словообразование способствует постоянному обновлению лексического состава и по своим эффектам, как писал А. Е. Супрун (100) имеет динамическую, инновационную, эволюционную природу.

С другой стороны, и аффиксальная, и композитная деривация опирается на уже существующие языковые ресурсы (корневые и аффиксальные морфемы), тем самым способствуя их закреплению в языковой системе, т.е. расширению класса производных единиц, соответствующих определенной словообразовательной модели. Тем самым словообразование, по мысли Супруна, функционирует как репродуктивная программа языковой деятельности, реализует стабилизирующую, консервирующую функцию.

В заголовке данного раздела словообразование обозначено как ресурс быстрого реагирования - неслучайно Н. А. Янко-Триницкая (259) писала о «нескончаемом потоке неологизмов». Основанием для такого сравнения служит факт, что новые явления в окружающей среде в первую очередь находят отражение в номинации, а здесь главную роль играет лексическая деривация ${ }^{2}$. Словообразовательные окказионализмы естественное проявление такой, рефлексивной (или реактивной), природы языка как системы знаковых репрезентаций. В лингвистической литературе подробно описаны разные аспекты окказиональности в сфере словообразования - можно упомянуть некоторые из публикаций: Земская; Канатаев и Янковская; Коряковцева Очерки о языке...; Коряковцева Интернационализация...; Коряковцева Окказионализмы...; Попова; Рацибурская Особенности новообразований..; Рацибурская Словообразовательные средства; Радбиль и др.; Юдина Новое в языке..; Юдина Окказионализмын... и др.

Значительную роль в инновационных процессах в области лексики играет словосложение (композиция). Например, Е. И. Коряковцева («Okkazionalizmy» 47) пишет об этом в связи с новыми номинациями в рекламе.

\footnotetext{
${ }^{2}$ При этом следует отметить, что функция словообразовательных средств не исчерпывается номинацией - помимо этого неологизмы употребляются (на фоне уже существующих, альтернативных наименований) для выражения оценки, для создания экспрессивного и рекреационного эффекта (см. Ильясова и Амири 90).
} 
Данное явление стало особенно заметным в последние десятилетия - под влиянием английского языка (Marinova). Так, А. О. Шишолина признает:

Появление большого количества композитов в современном русском языке связано [...] с активным процессом заимствования, которому сопутствует перенесение готовых лексических единиц из языка-источника или появление заимствованной модели, по которой строятся сложные новообразования на русской почве с участием ранее заимствованных или собственно русских элементов. (49)

Влияние английского языка проявляется не только в массовом характере данного типа номинации, но и в структуре неологизмов. Так, в русском языке композиты с нулевым интерфиксом имеют структуру: $x$ [определяемый элемент] $+y$ [определяющий элемент], например ${ }^{3}$ :

(1) КОВЕР-самолет [ковер, который является самолетом, сам летает]

(2) ВАГОН-ресторан [вагон, в котором находится ресторан]

(3) дом-интернат [дом, в котором находится интернат]

(4) ЧЕЛОВЕК-амфибия [человек, который является амфибией]

(5) ЧЕЛОВЕК-автомат [человек, который является автоматом, работает, как автомат]

(6) ЧЕЛОВЕК-машина [человек, который является машиной, работает, как машина]

В английских конструкциях подобного рода порядок элементов обратный:

(7) restaurant CAR [вагон, в котором находится ресторан]

(8) fashion HOUSE [дом, в котором производится модная одежда, обувь или аксессуары]

(9) advertising MAN [человек, который занимается рекламой, специалист по рекламе]

(10) maintenance MAN [человек, который занимается консервацией]

(11) garbage MAN [человек, который занимается уборкой мусора, мусорщик]

(12) effects MAN [человек, который занимается специальными эффектами]

(13) amphibian MAN [человек, который является амфибией]

\footnotetext{
${ }^{3}$ Определяемое (главное) слово выделено заглавными буквами.
} 
Под влиянием английского языка в русском языке последнего времени стали появляться композиты с определяющим элементом в первом позиции. Например, массовый характер имеет выражение онлайн-контакт со значением 'контакт в интернете, осуществляемый в режиме реального времени, ${ }^{4}$. По нормам русского языка порядок элементов должен быть обратным: контакт (какой?) > онлайн. Такие выражения также представлены в языковой практике, однако, по моим наблюдениям, составляют меньшинство.

Другой пример - название (построенного в 2014 г.) московского стадиона Открытие Арена. Структура данного выражения, с точки зрения системы русского языка, нетипичная: компонент Арена является главным и на этом основании должен находиться на первом месте. Компонент $\mathrm{Om}$ крытие имеет определяющую функцию и должен следовать вторым:

(14) Арена (какая?) > Открытие

Композиты исследуются лингвистами с разных точек зрения, например, с учетом грамматических характеристик компонентов, в частности, их частеречной принадлежности, или же с учетом происхождения компонентов (исконного или заимствованного). В данной работе собранный языковой материал будет описан с семантической точки зрения, а именно - с учетом семантической структуры словообразовательных окказионализмов как репрезентаций сложных понятий и стоящих за ними положений дел.

\section{2. СТРУКТУРНО-СЕМАНТИЧЕСКАЯ ТИПОЛОГИЯ КОМПОЗИТОВ С ЭЛЕМЕНТОМ КОРОНО}

Прежде всего следует отметить, что не все окказионализмы рассматриваемого нами семантического поля имеют композитный характер. В речевой практике довольно широко представлены примеры усечения (подробнее об этом явлении см.: Земская 110 и др.), т.е. употребление существительного корона в значении 'коронавирус', а также в других значениях, например: 'эпидемия коронавируса', 'коронавирусная инфекция’ и т. д. Вот несколько примеров:

\footnotetext{
${ }^{4} \mathrm{Cp}$. также подобные наименования: онлайн-платформа, онлайн-трансляция, онлайнпетиция, онлайн-чат, онлайн-торговля, онлайн-конструктор и многие другие.
} 
(15) У нее может вообще другой вирус или бактерия, но и корона ей уже обеспечена.

(16) В Боровске по официальным данным короной болеет 7 человек.

(17) Уже в середине июня федеральная земля планирует смягчить запрет на контакты, введенные для борьбы с пандемией короны.

(18) Семья с «короной»: история псковичей, заразившихся COVID-19.

Среди отмеченных имеются примеры высказываний, заимствованных из интернета, в которых фигурирует словоформа короно со значением 'коронавирусная эпидемия':

(19) Как достало это короно... чтоб он провалился куда-нибудь, к чёртовой тёте!!!

(20) Отвлекаете людей короно, а про бенз заткнулись.

(21) С этим короно чёрт-бы его побрал как сейчас рыбалка?

(22) Вот пришел этот короно так это неспроста вся Европа остановилась и вот в Венеции очистилась вода плавают дельфины прилетели лебеди.

Как видим, грамматический статус этого слова является неопределенным: в одних случаях оно выражает средний род (это короно), в других - мужской (короно...он).

В языковом материале представлено также суффиксальное словообразование - речь идет о дериватах коронавирусный, коронавирусник, коронавирусница. Встречаются и симбиотические окказионализмы, сочетающие в себе усечение и аффиксальный формант -ыч, ср.:

(23) Когда плохо ловит связь на сотовом, именно тогда антены передают короныч.

(24) У меня короныч.

(25) Короныч не пройдет.

(26) Змей Короныч (по аналогии: Змей Горыныц )

К этому же типу следует отнести и прилагательное коронныци в значении 'вызванный эпидемией коронавируса', которое выступает в предложении:

(27) Представители большой коалиции планируют сегодня, во вторник, провести переговоры о планируемом пакете мер для поддержки экономики, которая понесла урон в результате коронного кризиса. 
Основная масса неологизмов построена, однако, по композитному принципу, который сочетается с принципом усечения: из сочетания коронавирус устраняется второй элемент, а первый довольно свободно добавляется к другим словам, в основном - существительным. В результате этого возникают многочисленные окказионализмы: короно-кризис, короно-кризисный, короно-инфекция, короно-инфицированный, коронокарантин и др. Характерным примером данного типа словообразования может быть опубликованный в интернете рассказ Степана Дуплия $У$ короно-стены (Dupliy) - cp. несколько фрагментов:

(28) Всех и везде поставили к долгожданной и предсказываемой короно-стенке.

(29) Поверили во всё, что сказали по зомбоящику. Соглашаясь на все нелепые и ничего не приносящие короно-правила.

(30) Иные идут дальше и чувствуют себя короно-Толстыми и короно-Пушкиными, как минимум, засоряя несчастные литературные сервера короно-бредом.

(31) Если убрать это ключевое короно-слово из названия, то никто сейчас уже читать не будет, да и нечего, поскольку произведений без него уже не остается.

(32) Может короно-симфоний сочинят и короно-картин «злободневных» напишут? Короно-культура современности.

(33) [...] Поднять руки радостно, откатив на руке рубашку для безоговорочного восторженного приема прокалывания любым пойлом, чем они захотят, выдавая за «200\%-ную вакцину» - послушно играя в короно-игру.

(34) Для того и заваривалось это короно-всё.

(35) Невинные пациенты с иными сотнями болезней мужественно, скрипя зубами, молча «люди гибли за короно-металл».

(36) [...] Недолеченные, недосмотренные, за навар на этом всемирном шоу для единиц, «благодетелей» наших из золотого короно-миллиарда.

Н. А. Янко-Триницкая (259) писала о «семантической емкости» композитов, обеспечивающих «экономию речевых средств в процессе общения» (см. также: Шестак 444). За этим утверждением стоит признание факта, что композиты представляют собой продукты языковой компрессии (или конденсации) - они возникают на базе сложных пропозициональных протоструктур в результате имплицитации отдельных семантических элементов, при том что такая имплицитация может иметь более или менее интенсивный характер. С этим связано характерное свойство 
многих композитов - неоднозначность, аппроксимативность, т.е. возможность их двоякой, троякой и т.д. интерпретации (подробнее об этом см. Lüger 31 и др.).

Компрессированный характер имеет сам термин коронавирус: компоненты корона и вирус являются элементами пропозиционального отношения, которое на поверхностном уровне не выражено. Речь идет, как уже указывалось во Введении, о том, что вирус по своему виду (о чем свидетельствует наблюдение через микроскоп) НАПОМИНАЕТ солнечную корону (имеет округлую форму с выступами по своему периметру). Этот тип производности можно представить следующим образом:

короНавирус < ВИРУС (ТАКОЙ, ЧТО) НАПОМИНАЕТ (ПО СВОЕМУ ВИДУ) СОЛНЕЧНУЮ КОРОНУ

$\mathrm{x}$ y $<\mathrm{y}: \mathrm{P}(\mathrm{x}, \mathrm{y})$

Ранее (см. Kiklewicz 623 и др.) была предложена общая типология языковых конденсатов, которая может быть применена к описанию интересующих нас окказионализмов с компонентом короно-. В этой типологии различаются три деривационные модели, каждая из которых представляет процесс преобразования исходной семантической структуры более или менее сложного типа. В сжатой форме эти модели можно показать следующим образом:

МодеЛЬ 1: ПРЯМАЯ СЕМАНТИЧЕСКАЯ ЗАВИСИМОСТЬ

Пример: зубная боль

Синтаксическая деривация: зубная боль < Болит зуб

$\mathrm{x} \_\mathrm{p}<\mathrm{x}: \mathrm{P}(\mathrm{x})$

МоДеЛЬ 2: СЕМАНТИЧЕСКАЯ КООКУРЕНЦИЯ

Пример: зубной врач

Синтаксическая деривация: зубной врач < Врач лечит зубы

$\mathrm{x} \_\mathrm{y}<\mathrm{y}: \mathrm{P}(\mathrm{x}, \mathrm{y})$

МодеЛЬ 3: СЕМАНТИЧЕСКАЯ ТРАНЗИТИВНОСТЬ

Пример: зубное кресло

Синтаксическая деривация: зубное кресло < Врач лечит пацฺиенту зубы; Пациент сидит в кресле

$\mathrm{x} \_\mathrm{y}<\mathrm{y}: \mathrm{P}(\mathrm{x} \ldots) \& \mathrm{Q}(\mathrm{y} \ldots)^{5}$

${ }^{5}$ Символ конъюнкции (\&) является здесь условным, используемым с целью, чтобы не перегружать запись чрезмерной информацией. Я, разумеется, отдаю себе отчет в том, что между отдельными пропозициями могут устанавливаться разного рода отношения: целевые, результативные, квалитативные и т.д. 
Семантические протоструктуры не только относятся к области мотивации языковых конденсатов, но и представляют собой их лексическое содержание. Например, значение словосочетания зубной врач можно определить как 'врач, который лечит зубы / специалист по лечению зубов'.

Если обратиться к собранному языковому материалу, можно констатировать, что каждая деривационная модель представлена в разном объеме. Композиты с прямой семантической зависимостью членов не были обнаружены, тогда как вторая и третья деривационные модели имеют достаточно много реализаций. Они будут отдельно рассмотрены в следующих пунктах.

\section{1. КОМПОЗИТЫ С СЕМАНТИЧЕСКОЙ КООКУРЕНЦИЕЙ}

Содержание окказионализмов данной группы можно представить в виде пропозиции, в основе которой лежит некоторое невыраженное на поверхностном уровне предикативное отношение. В связи с тем, что здесь мы имеем дело с одной пропозицией, такие композиты будут именоваться как одночастные. Лексические компоненты, которые составляют сложное слово, отражают семантические аргументы, совместимые при одном и том же предикате. По отношению к этому предикату они, другими словами, являются соподчиненными. Символическая запись процесса деривации единиц данной группы, примеры которых (вместе с толкованием) приводятся ниже, соответствует приведенной выше формуле (2)

(37) короно-инфекция, короно-инфицированный < [инфекция, которая ВЫзВАНА коронавирусом]

(38) короно-пневмония [пневмония, которая ВызВАНА коронавирусом]

(39) короно-зараза $<$ [зараза, которая ВЫзВАНА коронавирусом]

(40) короно-носитель < [носитель, который ИМЕЕТ в своем организме коронавирус]

(41) короно-сами-знаете-что < [вы сами знаете, что СЛЕДУЕТ за словом «короно»]

(42) короно-монстр $<$ [монстр, с которым МОЖНО СРАВНИть коронавирус]

(43) короно-яйца ${ }^{7}$ [яйца, которые иМЕЕТ коронавирус]

\footnotetext{
${ }^{6}$ Предикат исходной пропозициональной структуры записан заглавными буквами, так чтобы было удобно выделять каждую пропозицию, особенно в тех случаях, когда их несколько (см. далее).

7 Этот неологизм встречается в стихотворении: На вирус мы ответим смехом Да прямо по короно-яйцам. Здесь мы имеем дело с весьма экзотичным примером персонификации
} 
В случае окказионализмов этой немногочисленной группы (7 единиц) имплицитация касается только одного элемента глубинной семантической структуры, а именно - пропозиционального предиката. Это, однако, не означает, что семантическая переработка данных композитов в сознании адресатов не встречает трудностей. Дело в том, что только некоторые семантические отношения реализуются в рамках одного семантического поля: коронавирус - инфекция - пневмония - зараза - носитель (ведущий компонент в таких случаях обычно называет явления, вызываемые коронавирусом), тогда как другие отношения имеют случайный и, с коммуникативной точки зрения, экзотический характер: коронавирус-монстр, коронавирус - сами-знаете-что, коронавирус - яйца.

\section{2. КОМПОЗИТЫ С СЕМАНТИЧЕСКОЙ ТРАНЗИТИВНОСТЬЮ}

Семантическая транзитивность означает ассоциативное отношение между семантическими аргументами, которые относятся к разным пропозициям. Исходная семантическая протоструктура, по сравнению с предыдущим типом, имеет более сложный характер: она включает две, три или четыре пропозиции, в связи с чем соответствующие протоструктуры будут трактоваться как двух-, трех- и четырехчастные.

\subsection{1. КОМПОЗИТЫ С ДВУХЧАСТНЫМИ ПРОТОСТРУКТУРАМИ}

Символическое представление обобщенной семантики единиц данной группы соответствует формуле (3). Она показывает, что элементы сложного слова $(x, y)$ на семантическом уровне относятся к разным пропозициям, между которыми существует определенная связь. Кроме этого обязательным свойством таких протоструктур является кореференция (на которую в формуле указывает повторяющееся многоточие), т.е. наличие общего аргумента ${ }^{8}$. Ниже приводятся отмеченные примеры композитов данного типа, которые были разделены на несколько групп. Прежде всего следует отметить композиты (18 единиц) с каузативной семантикой: предметом номинации является некоторое состояние или положение дел (в социальной или эмоциональной сфере), вызванное эпидемией коронавируса или коронавирусной инфекцией:

коронавируса: автор стихотворения представляет коронавирус как противника, которого он ударяет по яйцам.

${ }^{8}$ В случае словосочетания зубное кресло таким элементом является [пациент]. 
(44) короно-кризис, короно-кризисный < [кризис, который ВЫЗВАН эпидемией, которая ВЫзВАНА коронавирусом]

(45) короно-бунт < [бунт, который был ВЫзВАН эпидемией, которая ВЫЗВАНА коронавирусом]

(46) короно-паранойя < [паранойя, которая ВЫзВАНА эпидемией, которая ВЫЗВАНА коронавирусом]

(47) короно-бесие < [бесие, т.е. безумие, безрассудность, неконтролируемое поведение, которое ВЫЗВАНО эпидемией, которая ВЫзВАНА коронавирусом]

(48) короно-шухер [шухер, т.е. опасность, которая ВызВАНА эпидемией, которая ВЫЗВАНА коронавирусом]

(49) короно-истерия < [истерия, которая ВЫзВАНА эпидемией, которая ВЫзВАНА коронавирусом]

(50) короно-карантин < [карантин, который ВЫзВАН эпидемией, которая ВЫЗВАНА коронавирусом]

(51) короно-паника < [паника, которая ВЫзВАНА эпидемией, которая ВЫзВАНА коронавирусом]

(52) короно-пандемия < [пандемия, которая ВЫзВАНА инфекцией, которая ВЫЗВАНА коронавирусом]

(53) короно-апокалипсис < [апокалипсис, который ВызВАН эпидемией, которая ВЫЗВАНА коронавирусом]

(54) короно-ужас < [ужас, который ВЫзВАН эпидемией, которая ВЫзВАНА коронавирусом]

(55) короно-ситуация < [ситуация, которая ВЫзВАНА эпидемией, которая ВЫзВАНА коронавирусом]

(56) короно-смерть < [смерть, которая ВЫзВАНА инфекцией, которая ВЫзВАНА коронавирусом]

(57) короно-стресс < [стресс, который ВЫЗВАН эпидемией, которая ВЫЗВАНА коронавирусом]

(58) короно-иизофрения < [шизофрения, которая ВЫзВАНА эпидемией, которая ВЫЗВАНА коронавирусом]

(59) короно-запой < [запой, который ВЫзВАН эпидемией, которая ВЫзВАНА коронавирусом]

(60) короно-мракобесие < [мракобесие, которое ВЫЗВАНО эпидемией, которая ВызВАНА коронавирусом] 
Ко второй группе (12 единиц) относятся композиты, предметом номинации которых является положение дел, состояние или действие, которое относится к периоду длительности эпидемии коронавируса:

(61) короно-пициа [пицца, которую курьеры достАВляют индивидуальным клиентам во время эпидемии, которая ВЫзВАНА коронавирусом]

(62) короно-мошенники [мошенники, которые дЕйствУЮт во время эпидемии, которая ВЫзВАНА коронавирусом]

(63) короно-креатив [креатив, который ИМЕЕТ МЕСТО во время эпидемии, которая ВЫЗВАНА коронавирусом]

(64) короно-бизнес < [бизнес, которым ЗАНИМАЮТСя предприниматели во время эпидемии, которая ВЫЗВАНА коронавирусом]

(65) короно-продажи < [продажи, которая РЕАЛИЗуюТСя во время эпидемии, которая ВЫЗВАНА коронавирусом]

(66) короно-отпуск < [отпуск, который ИМЕЕТ МЕСТО во время эпидемии, которая вЫзВАНА коронавирусом]

(67) короно-ивент < [ивент, т.е. событие, которое ИМЕЕТ МЕСТО во время эпидемии, которая ВЫзВАНА коронавирусом]

(68) короно-пауза < [пауза, которая иМЕЕТ МЕСТО во время эпидемии, которая ВЫЗВАНА коронавирусом]

(69) короно-вечеринка < [вечеринка, которая ИМЕЕТ МЕСТО во время эпидемии, которая ВЫзВАНА коронавирусом]

(70) короно-шоу < [шоу, которое ИМЕЕТ МЕСТО во время эпидемии, которая ВЫЗВАНА коронавирусом]

(71) короно-сводка < [сводка, которая КАСАЕТСя числа заболеваний и смертей во время эпидемии, которая ВЫзВАНА коронавирусом]

(72) короно-фокус ${ }^{9}<$ [фокус, который КАСАЕТСя эпидемия, которая ВЫЗВАНА коронавирусом]

Третью группу (6 единиц) составляют композиты, в которых эпидемия коронавируса является предметом сообщения, коммуникативного действия или события:

(73) короно-история < [история, тема которой КАСАЕТСЯ эпидемии, которая ВЫЗВАНА коронавирусом]

(74) короно-драма < [драма, тема которой КАСАЕТСЯ эпидемии, которая ВЫзВАНА коронавирус]

\footnotetext{
${ }^{9}$ Текст: Поэт Маленко выкинул короно-фокус.
} 
(75) короно-фестный (короно-фестная программа) < [касается фестиваля, тема которого КАСАЕТСЯ эпидемии, которая ВЫЗВАНА коронавирус]

(76) короно-мем [мем, который (тема которого) КАСАЕТСЯ коронавируса, которая ВЫзВАНА коронавирусом]

(77) короно-выпуск < [выпуск (номер периодического издания), который (тема которого) КАСАЕТСЯ эпидемии, которая ВЫЗВАНА коронавирус]

(78) короно-прикол < [прикол, темой которого ЯВЛЯЕТСЯ эпидемия, которая ВЫЗВАНА коронавирусом]

Оставшиеся единицы этой категории трудно сгруппировать в какойнибудь класс или классы - отношения между контрагентами $x \_y$ слишком разнородные, поэтому я приведу их списком:

(79) короно-анализ < [анализ, который ПОКАЗЫВАЕТ, ИМЕЕТСЯ ли в организме человека коронавирус]

(80) короно-тест < [тест, который ПОКАЗЫВАЕТ, ИМЕЕТСЯ ли в организме человека коронавирус]

(81) короно-арбидол < [арбидол (таблетки), который ДЕЙсТВУЕТ против инфекции, которая ВЫзВАНА коронавирусом]

(82) короно-изоляџия < [изоляция, которая ПРИМЕНЯЕТСЯ к людям, в организме которых ИМЕЕТСЯ коронавирус]

(83) короно-сражение < [сражение, которое ВЕдУТ люди против эпидемии, которая ВызВАНА коронавирусом]

(84) короно-здоровье < [здоровье, которое люди дОлЖНЫ СОХРАНИТь несмотря на эпидемию, которая ВЫЗВАНА коронавирусом]

(85) короно-сопли < [сопли, которые РАСПУСКАЮТ некоторые люди в связи с эПидемией, которая ВЫЗВАНА коронавирусом]

(86) короно-день < [день, который ОтНОСИТСЯ к периоду эпидемии, которая ВЫЗВАНА коронавирусом]

(87) короно-имунный < [человек, который ОБЛАДАЕТ иммунитетом к инфекции, которая ВызВАНА коронавирусом $]^{10}$

(88) короно-нефтяной (короно-нефтяной обвал) < [ОБВАЛ, СНИЖЕНИЕ продукции и продажи нефти во время эпидемии, которая ВЫЗВАНА коронавирусом]

Следует отметить, что композиты данной группы (46 единиц), в основном, представляют собой наименования событий, состояний и явле-

\footnotetext{
${ }^{10}$ Данный композит функционирует как существительное, ср. контекст его употребления: Говорят только короно-имунным можно будет на вечеринки.
} 
ний, которые вызваны эпидемией коронавируса, имеют место во время эпидемии или передают сообщения о ней. Эти наименования не имеют прямого отношения к инфекции, к процессу протекания болезни или к эпидемии - они относятся к пограничным сферам человеческой жизнедеятельности, которых так или иначе коснулась эпидемия коронавируса.

\subsection{2. КОМПОЗИТЫ С ТРЕХЧАСТНЫМИ ПРОТОСТРУКТУРАМИ}

В материале отмечено также некоторое количество окказионализмов, которые реализуют семантическую структуру с тремя пропозициями. В обобщенном виде ее можно представить так:

$x \_y<y: P(x \ldots) \& Q(\ldots) \& R(y \ldots)$

В этой категории выделяется относительно однородная группа единиц с ведущим компонентом, называющим место или учреждение, в котором происходят события, связанные с коронавирусной инфекцией в основном, это лечебные заведения:

(89) короно-барак < [барак, в котором НАХодятСя люди, которые БОлЕЮТ в результате того, что они ЗАРАЗИлись коронавирусом]

(90) короно-больница < [больница, в которой НАХОДяТСя люди, которые БОЛЕЮТ в результате того, что они ЗАРАЗИЛИСь Коронавирусом]

(91) короно-центр < [центр, которЫЙ ЗАНИМАЕТСЯ ЛЕЧЕНИЕМ ЛЮдей, БОЛЕЮТ в результате того, что они ЗАРАЗИЛИСь коронавирусом]

(92) короно-такси < [такси, которые ПЕРЕВОзяТ людей, которые БОЛЕЮТ в результате того, что они ЗАРАЗИЛИСЬ коронавирусом]

(93) короно-койка < [койка (в больнице), на которой лЕжит человек, который БОЛЕЕТ в резУЛЬтате того, что он ЗАРАЗИЛСЯ коронавирусом]

Кроме того композиты данной группы являются наименованиями событий и явлений, имеющих то или иное отношение к последствиям эпидемии коронавируса или, чаще, коронавирусной инфекции, при этом характер этого отношения значительно варьируется:

(94) короно-статистика $<$ [статистика, которая КАСАЕТСЯ количества заболеваний и смертельных исходов, которые ПрОИзошли во время эпидемии, которая ВЫЗВАНА коронавирусом] 
(95) короно-обострение < [обострение, которое ПРОИСХОдиТ в ситуации, когда человек БОЛЕЕТ в результате того, что он ЗАРАЗИЛСЯ коронавирусом]

(96) короно-обман < [обман, который иМЕЕТ МЕСТО в СМИ (и в других публичных сферах) в связи количеством Людей, которые ЗАБОЛЕЛИ ИЛИ УМЕРЛИ в результате инфекции, которая ВЫЗВАНА коронавирусом]

(97) короно-хомячок < [человек, коТорЫЙ НАПОМИНАЕТ Хомячка тем, чТо ДЕЛАЕТ ЗАПАСЫ во время эПидемии, которая ВЫЗВАНА коронавирусом]

(98) короно-политик < [Политик, которЫй ДЕЙСТВУЕТ с цеЛЬю / НАСТАИВАЕТ на том / ЗАИНТЕРЕСОВАНЫ в том, чТобЫ ОГРАНИЧИВАТЬ ПОВедение людей во время эпидемии, которая ВЫЗВАНА коронавирусом]

(99) короно-детектив [детектив, который РАССЛЕДУЕТ преступления или нарушения, которые люди СОВЕРШАЮТ вопреки ограничениям поведения во эпидемии, которая ВЫЗВАНА коронавирусом]

(100) короно-провал < [провал, который ПРОИзОШЕЛ в процессе мероприятий, которые осущЕствляЮтся против эпидемии, которая вызвана коронавирусом]

(101) короно-диверсия < [диверсия, которая НАПРАВЛЕНА против того, чтобЫ ОТМЕНИТЬ иЛИ УМЕНЬШИТЬ ограничения поведения людей во время эпидемии, которая ВЫЗВАНА коронавирусом]

(102) короно-Майдан < [действия, которые НАПОМИНАЮТ события на киевском Майдане и которые НАПРАВЛЕНЫ против эпидемии, которая вызвана коронавирусом]

(103) короно-шизанутый ${ }^{11}<$ [человек, который является ШИЗАНУТЫМ, НЕНОРМАЛЬНЫМ, СТРАННЫМ с точки зрения того, как он ВЕДЕТ себя во время эПидемиИ, которая ВЫзВАНА коронавирусом]

В данной группе имеются также композиты с ведущим компонентом - прилагательным:

(104) короно-положительный (короно-положительные результаты анализов) < [ПОЛОжИТЕЛЬНЫЕ результаты анализов, которые должны были выявИТь, ИМЕЕТСЯ ли в организме человека коронавирус]

(105) короно-духовный (короно-духовные скрепы) < [человек НУЖДАЕТСЯ в духовных скрепах, чтобы жить во время эпидемии, которая ВЫзВАНА коронавирусом]

Данная группа, как видим, с семантической точки зрения весьма разнородна: композиты служат для наименования предметов, операций (действий), процессов, состояний и свойств, которые связаны с последствиями

\footnotetext{
${ }^{11}$ Употребляется как субстантивированное прилагательное.
} 
заражения коронавирусом. Следует отметить, что из 17 единиц большинство (а именно - 10, т.е. около 60\%) представляют собой конкретные существительные (койка, барак, политик, детектив, диссидент и др.) - в предыдущей группе их число значительно меньше.

\subsection{3. КОМПОЗИТЫ С ЧЕТЫРЕХЧАСТНЫМИ ПРОТОСТРУКТУРАМИ}

В материале отмечено несколько единиц, в содержании которых можно выделить четыре пропозиции:

(106) короно-ситр < [автомобиль марки «Ситроен», который ПРИШЕЛ В НЕГОДНОСть подобно тому, как ПРИХодиТ в НЕГОДНОСть организм человека, который ЗАБОЛЕЛ в результате инфекции, которая ВЫзВАНА коронавирусом]

(107) короно-партизан < [человек, который скрытно дЕЙСтвУЕТ вопреки тому, что действия людей во время эпидемии, которая ВЫЗВАНА коронавирусом, ОГРАничЕНЫ, подобно тому, как ДЕйСтвУют партизаны]

(108) короно-зомби < [люди, которые дЕйствуют в соответствии с предписаниями, которые ДЕЙствУЮТ во время эпидемии, которая ВЫзВАНА коронавирусом, как/подобно тому, что ВЕдУт себя как зомби]

(109) короно-диссидент, короно-дисс < [человек, который дЕЙСтВУЕТ вопреки тому, что поведение людей во время эпидемии, которая ВЫзВАНА коронавирусом, ОГРАНИЧЕНО, Подобно томУ, как ДЕЙСТВУЕТ диссидент]

(110) (первая) короно-ласточка < [(первый) признак, который СВИдЕТЕЛЬСТВУЕТ о том, что ИМЕЕТ МЕСТО эпидемия, которая ВЫЗВАНА коронавирусом, подобно тому, как первая ласточка СвидЕТЕльСтвУЕТ о начале весны]

Общее пропозициональное содержание данных композитов можно представить в виде формулы:

$x \_y<y: P(x \ldots) \& Q(\ldots) R(\ldots) \& S(y \ldots)$

Приведенные выше семантические интерпретации показывают, что во всех случаях имеется сравнение: поломка автомобиля сравнивается с заболеванием человека в результате инфекции коронавируса; первые симптомы короноинфекции сравниваются с ласточкой как вестницей весны; люди, скрытно действующие вопреки предписаниям, сравниваются с партизанами и т.д. 


\section{3. ИНТЕРПРЕТАЦИЯ РЕЗУЛЬТАТОВ АНАЛИЗА}

Каждая номинация представляет собой когнитивный процесс, в котором задействован человеческий опыт - знания и убеждения, имеющие общий (в рамках данного культурного сообщества) или идиосинкратический (групповой, субкультурный, личный) характер ${ }^{12}$. Хотя в семантической структуре композита вершинную позицию занимает второй компонент, что отражено в семантическом толковании:

\section{короно-кризис}

[кризис, который ВЫЗВАН эпидемией, которая ВЫзВАНА коронавирусом]

с точки зрения репрезентации знаний базовой является информация, связанная с первым компонентом. Все приведенные окказиональные единицы опираются на знание носителей языка о короноинфекции и эпидемии коронавируса. В связи с этим когнитивная предыстория композитов включает два блока: известную, пресуппозитивную и новую, ассертивную информацию:

ПРЕСУППОЗИЦИЯ:

Я знаю, что коронавирус вызвал эпидемию.

АССЕРЦИЯ:

Я сообщаю, что эпидемия вызвала кризис.

Двух-, трех- и четырехчастные протоструктуры различаются объемом пресуппозитивной информации, на что указывают следующие примеры:

\section{короно-провал}

ПРЕСУППОЗИЦИЯ:

Я знаю, что коронавирус вызвал эпидемию.

Я знаю, что во время эпидемии осуществляются ограничительные мероприятия.

\section{АССЕРЦИЯ:}

Я сообщаю, что произошел провал этих мероприятий.

\section{короно-диссидент}

ПРЕСУППОЗИЦИЯ:

Я знаю, что коронавирус вызвал эпидемию. (395).

12 Применительно к номинациям в интернет-коммуникации об этом пишет А. А. Чувакин 
Я знаю, что во время эпидемии поведение людей ограничено.

Я знаю, что диссидент - это человек, взгляды и поведение которого радикально расходятся с общепринятыми.

АССЕРЦИЯ:

Я сообщаю, что некоторые люди, подобно диссидентам, ведут себя во время эпидемии коронавируса вопреки общепринятым предписаниям.

Пресуппозитивная информация обычно выходит за границы стандартной лексической компетенции «среднестатического» носителя русского языка, поэтому в процессе семантической переработки окказиональных композитов происходит инференция - привлечение знаний общего (энциклопедического) или специального характера. В принципе, это может вызывать определенные трудности в процессе семантической интерпретации некоторых окказионализмов, например, таких, как короно-день, короно-сражение, короно-сопли, короно-такси, короно-ласточка и др. $\mathrm{C}$ другой стороны, такие опасения могут быть излишними с учетом того, что обычно окказионализмы появляются и фигурируют в среде так называемых интернет-сообществ с общим фоном базовых знаний (системы пресуппозиций), а кроме того их понимание облегчается за счет контекста.

Можно было заметить, что степень имплицитации семантической протоструктуры связана с характером заполнения позиции второго компонентов - с точки зрения его принадлежности к категории абстрактных или конкретных наименований. На это указывает следующая таблица.

\begin{tabular}{|l|c|c|}
\hline \multirow{2}{*}{$\begin{array}{c}\text { Тип } \\
\text { протоструктуры }\end{array}$} & \multicolumn{2}{|c|}{$\begin{array}{c}\text { Количество компонентов } \\
\text { (во второй позиции) }\end{array}$} \\
\cline { 2 - 3 } & $\begin{array}{c}\text { с абстрактным } \\
\text { значением }\end{array}$ & $\begin{array}{c}\text { с конкретным } \\
\text { значением }\end{array}$ \\
\hline \hline Двухчастная & 44 & $2(4,3 \%)$ \\
\hline Трехчастная & 7 & $10(58,8 \%)$ \\
\hline Четырехчастная & 2 & $11(85 \%)$ \\
\hline
\end{tabular}

Как видим, семантическая структура композитов с конкретным значением второго компонента имеет статистически более сложный характер. Другими словами, такие композиты представляют собой результат 
более сильной имплицитации семантической протоструктуры. Это можно объяснить тем, что предметные имена, о чем, кстати, пишет Е. В. Рахилина (28), не обладают, в отличие от глаголов, «жесткой сочетаемостью», т.е. свойством синтаксической коннотации (обусловливания сопутствующих пропозициональных позиций), поэтому предметные имена совмещаются в одной пропозиции благодаря наличию общего предиката (как третьего компонента), тогда как сочетаемость предметного и предикатного имени может быть непосредственной.

Следует также отметить, что несмотря на разговорный характер окказионализмов, большинство из них выполняет номинативную функцию, тогда как композиты, маркированные с точки зрения экспрессивности или оценки, представлены очень редко - к ним можно отнести такие единицы, как короно-зомби, короно-Майдан, короно-диверсия, короно-шизанутый, короно-сопли, короно-бесие и немногие другие.

\section{ЗАКЛЮЧЕНИЕ}

В статье было рассмотрено 76 лексических единиц - окказиональных композитов с первым компонентом короно-, отмеченные в среде интернета, а именно - в журналистских текстах, в постах социальных сетей, интернет-форумов и в комментариях. Разумеется, нельзя считать, что этот список исчерпывает все бытующие в интернете неологизмы данного типа: во-первых, охватить полный объем электронных текстов не представляется возможным, а во-вторых, эта группа лексикона постоянно обновляется.

Анализ показал, что окказионализмы реализуют разные типы семантических структур с одной, двумя, тремя или четырьмя пропозициями. Наиболее многочисленную группу (60\%) составляют композиты с двухчастной семантической структурой, которые в большинстве называют события или явления, вызванные эпидемией коронавируса или происходящие во время эпидемии. Степень имплицитации пропозициональных компонентов является при этом умеренной: более сильной, чем в случае композитов с семантической коокуренцией, но более слабой, чем в случае трех- и четырехчастных семантических протоструктур.

Собранные и проанализированные в статье единицы трактуются как окказиональные - с учетом того, что они не отражены в новейших словарях. В большинстве случаев мы имеем дело с однократными номина- 
циями, хотя некоторые лексемы получают более широкое распространение и не исключено, что через некоторое время они будут кодифицированы. Например, это относится к композиту короно-кризис - в поисковой системе Яндекс.ру можно получить доступ к более 2 тыс. документов с этим словом.

В статье отмечалось, что процессы лексической деривации, которые приводят к возникновению окказионализмов, опираются на когнитивную систему носителей современного русского языка. Семантическая реконструкция композитов позволяет утверждать, что коронавирус в большинстве случаев трактуется как каузатор (или эффектор), т.е. как причина инфекции или, чаще, эпидемии, которая - в свою очередь рассматривается как социальное явление, детерминирующее поведение людей, административные решения (например, запреты и ограничения), содержание публичной коммуникации и др. Если мы обратимся к тексту «Пира во время чумы» А. С. Пушкина, то можем прочитать о мраке, «[...] который ныне // Зараза, гостья наша, насылает // На самые блестящие умы». Как видим, и во времена Пушкина зараза представлялась в структуре фрейма детерминации. Впрочем, есть и различие: проанализированный в статье материал окказиональных композитов не дает оснований для утверждения о персонификации заразы.

\section{БИБЛИОГРАФИЯ}

Castells, Manuel. «Communication power: mass communication, mass self-communication, and power relationship in the network society». Media and society, edited by James Curran, Blomsbury Academic, 2010, pp. 3-17.

Chuvakin, A[leksey] A[ndreyevich]. «Internet-kommunikatsiya: miniatyura v prostranstve vtorichnykh tekstov». Problemy rechevoy kommunikatsii, VIII, red. M. A. Kormilitsyna i O. B. Sirotinina, Izd-vo Sarat. un-ta, 2008, ss. 385-401 [Чувакин, А[лексей] А[ндреевич]. «Интернет-коммуникация: миниатюра в пространстве вторичных текстов». Проблемы речевой коммуникации, VIII, ред. М. А. Кормилицына и О. Б. Сиротинина, Изд-во Сарат. ун-та, 2008, сс. 385-401].

Dupliy, Stepan. «U korono-steny». Proza.ru, proza.ru/2020/05/17/914. Dostup 25.02.2021 [Дуплий, Степан. «У короно-стены». Проза.py, proza.ru/2020/05/17/914. Доступ 25.02. 2021].

Il'yasova, S[vetlana] V[asil'yevna], i L[yudmila] P[yetrovna] Amiri. Yazykovaya igra v kommunikativnom prostranstve SMI i reklamy. Flinta, 2009 [Ильясова, С[ветлана] В[асильевна], и Л[юдмила] П[етровна] Амири. Языковая игра в коммуникативном пространстве СМИ и рекламы. Флинта, 2009]. 
Kanatayev, D[mitriy] V[ladimirovich], i A. N. Yankovskaya. «Sposoby obrazovaniya okkazional'noy leksiki na primere sovremennykh amerikanskikhvoyennykh materialov». Filo$\operatorname{logos}$, no. 37(2), 2018, ss. 26-33 [Канатаев, Д[митрий] В[ладимирович], и А. Н. Янковская. «Способы образования окказиональной лексики на примере современных американских военных материалов». Филоlogos, № 37(2), 2018, cс. 26-33].

Kiklewicz, Aleksander. „Affiksal'naya derivatsiya i sintaksicheskaya kompressiya” [„Аффиксальная деривация и синтаксическая компрессия"], t. 63, nr 4, Slavia Orientalis, 2014, ss. 612-628.

Koryakovtseva, Y[elena] I[vanovna]. «Internatsionalizatsiya, demokratizatsiya i 'mediatizatsiya' slavyanskikh yazykov v usloviyakh globalizatsii (slovoobrazovatel'nyy·aspekt)» [Коряковцева, Е[лена] И[вановна]. «Интернационализация, демократизация и 'медиатизация» славянских языков в условиях глобализации (словообразовательный аспект)»]. Globalizacja a języki stowiańskie. Globalization and Slavic languages, red. Elena I. Koriakowcewa, Wydawnictwo Uniwersytetu Przyrodniczo-Humanistycznego w Siedlcach, 2018, ss. 33-47.

Koryakovtseva, Yelena. "Okkazionalizmy v reklamnykh tekstakh: k voprosu o kognitivnom kodirovanii (na materiale russkogo i pol'skogo yazykov)» [Коряковцева, Елена. «Окказионализмы в рекламных текстах: к вопросу о когнитивном кодировании (на материале русского и польского языков)»]. Acta Universitatis Lodziensis, Folia Linguistica Rossica, nr 15, 2018, ss. 43-52.

Koryakovtseva, Y[elena] I. Ocherki o yazyke sovremennykh slavyanskikh SMI (semantiko-slovoobrazovatel'nyy lingvokul'turologicheskiy aspekty [Коряковцева, Елена И. Очерки о языке современных славянских СМИ (семантико-словообразовательный и лингвокультурологический аспекты)]. Wydawnictwo Uniwersytetu Przyrodniczo-Humanistycznego w Siedlcach, 2016.

Lüger, Heinz-Helmut. Pressesprache. Max Niemeyer, 1995.

Marinova, Y[elena] V[yacheslavovna]. Teoriya zaimstvovaniya v osnovnykhponyatiyakh i terminakh. Flinta, 2013. [Маринова, Е[лена] В[ячеславовна]. Теория заимствования в основных понятиях и терминах. Флинта, 2013].

Popova, T[at'yana] V[aler'yevna]. Russkaya neologiya i neografiya. UGTU-UPI, 2005 [Попова, Т[атьяна] В[алерьевна]. Русская неология и неография. УГТУ-УПИ, 2005].

Radbil', Timur Ben'yuminovich, i dr. Sotsiokul'turnyye i lingvopragmaticheskiye aspekty sovremennykh slovoobrazovatel'nykh protsessov. Flinta, 2018 [Радбиль, Тимур Беньюминович, и др. Социокультурные и лингвопрагматические аспекты современных словообразовательных прочессов. Флинта, 2018].

Rakhilina, Y[ekaterina] V[ladimirovna]. Kognitivnyy analiz predmetnykh imen.Semantika i sochetayemost'. Russkiye slovari, 2000 [Рахилина, Е[катерина] В[ладимировна]. Когнитивный анализ предметных имен. Семантика и сочетаемость. Русские словари, 2000].

Ratsiburskaya, Larisa [Viktorovna]. «Slovoobrazovatel'nyye sredstva otsenki sotsial'no znachimykh lits v rossiyskikh media» [Рацибурская, Лариса [Викторовна]. «Словообразовательные средства оценки социально значимых лиц в российских медиа»]. Wizerunek jako kategoria teorii komunikacji, antropologii kultury i semiotyki tekstu, red. Aleksander Kiklewicz, Centrum Badań Europy Wschodniej, 2020, ss. 213-223.

Ratsiburskaya, Larisa [Viktorovna]. "Osobennostinovoobrazovaniy v sovremennykh sredstvakh massovoy informatsii». Vestnik Nizhegorodskogo universiteta im. N. I. Lobachevskogo,seriya: filologiya, no. 1, 2003, ss. 111-116 [Рацибурская, Лариса [Викторовна]. 
«Особенности новообразований в современных средствах массовой информации». Вестник Нижегородского университета им. Н. И. Лобачевского, серия: филология, № 1, 2003, cc. 111-116].

Shestak, L. A. «Sovremennyy russkiy yazyk - eto rasshireniye vozmozhnostey sistemy?» Problemy rechevoy kommunikatsii, VIII, red. M. A. Kormilitsyna i O. B. Sirotinina, Izd-vo Sarat. un-ta, 2008, ss. 443-446 [Шестак, Л. А. «Современный русский язык - это расширение возможностей системы?» Проблемы речевой коммуникации, VIII, ред. М. А. Кормилицына и О. Б. Сиротинина, Изд-во Сарат. ун-та, 2008, сc. 443-446].

Shisholina, O. A. «Tipologiya noveyshikh kompozitov russkogo yazyka». Vestnik Orenburgskogo gosudarstvennogo universiteta, no. 4 (192), 2016, ss. 49-53 [Шишолина, О. А. «Типология новейших композитов русского языка». Вестник Оренбургского государственного университета, № 4 (192), 2016, сс. 49-53].

Suprun, A. Ye. «Dualizm slovoobrazovaniya, diakhroniya i sinkhroniya». Sopostavitel'noye izucheniya slovoobrazovaniya slavyanskikh yazykov, red. G. P. Neshchimenko, Nauka, 1987, ss. 99-104 [Супрун, А. Е. «Дуализм словообразования, диахрония и синхрония». Сопоставительное изучения словообразования славянских языков, ред. Г. П. Нещименко, Наука, 1987, сс. 99-104].

Yanko-Trinitskaya, N. A. Slovoobrazovaniye v sovremennom russkom yazyke. Indrik, 2001 [ЯнкоТриницкая, Н. А. Словообразование в современном русском языке. Индрик, 2001].

Yudina, A. D. «Novoye vyazyke periodiki i okkazional'nom slovoobrazovanii». Mova, no. 20, 2013, ss. 180-185 [Юдина, А. Д. «Новое в языке периодики и окказиональном словообразовании». Мова, № 20, 2013, сс. 180-185].

Yudina, A. D. Okkazionalizmy, motivirovannyye imenami sobstvennymi». Izvestiya Rossiyskogo gosudarstvennogo pedagogicheskogo universiteta im. A. I. Gertsena, no. 195, 2020, ss. 126-134 [Юдина, А. Д. «Окказионализмы, мотивированные именами собственными». Известия Российского государственного педагогического университета им. А. И. Гериена, № 195, 2020, сc. 126-134].

Zemskaya, Ye. A. Russkaya razgovornaya rech': lingvisticheskiy.analiz i problemy obucheniya. Russkiy yazyk, 1979. [Земская, Е. А. Русская разговорная речь: лингвистический анализ и проблемы обучения. Русский язык, 1979].

\section{KORONO-KOMPOZYTY W JEZZYKU ROSYJSKIM}

Streszczenie

Tematem artykułu są procesy słowotwórcze, prowadzące do pojawienia się okazjonalnych kompozytów z pierwszym składnikiem korono- w najnowszym języku rosyjskim. Autor odnotowuje aktywność tego typu słowotwórstwa i tego rodzaju kompozytów w tekstach dziennikarskich, a także w komunikacji członków społeczności internetowych (w sieciach społecznościowych, na forach internetowych itp.). Zebrany przez autora (76 okazjonalnych kompozytów) materiał językowy został opisany z semantycznego punktu widzenia, tzn. pod względem protostruktur semantycznych, reprezentujących plan treści kompozytów. Wyróżnia się dwie kategorie takich struktur: kookurencja semantyczna i tranzytywność semantyczna. Autor osobno opisuje kompozyty o protostrukturach jedno-, dwu-, trzy- i czteroczęściowych.

Słowa kluczowe: rosyjskie słowotwórstwo; okazjonalizm; kompozyt; kompresja; implicytacja; model derywacyjny; protostruktura semantyczna; propozycja. 


\section{CORONO-COMPOSITES IN THE RUSSIAN LANGUAGE}

\section{S u m m a ry}

The topic of this article is the word-formation processes leading to the appearance of occasional composites with the initial component corono- in contemporary Russian. The author notes the usage of this type of word formation and composites in journalistic texts, as well as in the communication between members of online communities (on social networks, Internet fora, etc.). The language material collected by the author ( 76 occasional composites) is described from a semantic point of view, i.e. in terms of semantic protostructures, representing the plan of content of the composites. There are two categories of such structures: semantic co-occurrence and semantic transitivity. The author separately describes the composites with one-, two-, threeand four-part protostructures.

Keywords: Russian word formation; occasional word; composite; compression; implication; derivative model; semantic protostructure; proposition. 